\title{
Rapid Arrival and Integration of Ascending Sensory Information in Layer 1 Nonpyramidal Neurons and Tuft Dendrites of Layer 5 Pyramidal Neurons of the Neocortex
}

\author{
Yinghua $\mathrm{Zhu}^{1}$ and J. Julius $\mathrm{Zhu}^{1,2,3}$ \\ ${ }^{1}$ Department of Pharmacology, University of Virginia School of Medicine, Charlottesville, Virginia 22908, ${ }^{2}$ Cold Spring Harbor Laboratory, Cold Spring \\ Harbor, New York 11724, and ${ }^{3}$ Department of Cell Physiology, Max Planck Institute for Medical Research, Heidelberg D-69120, Germany
}

\begin{abstract}
Ascending sensory inputs arriving in layer 1 of the neocortex carry crucial signals for detecting salient information; but how the inputs are processed in layer 1 is unknown. Using a whole-cell in vivo recording technique targeting nonpyramidal neurons in layer 1 and tuft dendrites of layer 5 pyramidal neurons in layers 1-2, we examined the processing of these ascending sensory inputs in the barrel cortex. Here, we show that local circuit and deeper-layer-projecting neurons in layer 1, as well as tuft dendrites and somata of layer 5 pyramidal neurons, respond to multiple whiskers (6-15) with robust EPSPs. Remarkably, the latency for primary whisker-evoked responses is as short as $\sim 5-7 \mathrm{msec}$ in layer 1 neurons and tuft dendrites of layer 5 pyramidal neurons. In addition, the latency for primary whiskerevoked responses in tuft dendrites of layer 5 pyramidal neurons is $\sim 1 \mathrm{msec}$ shorter than that in somata. These results indicate that ascending sensory inputs arrive in layers 1 and 4 concurrently, which provides a neural mechanism for rapid integration and coincident detection of salient sensory information.
\end{abstract}

Key words: rat; somatosensory; excitation; inhibition; whisker; attention

\section{Introduction}

Layer 1 of the neocortex, a unique layer containing mainly nonpyramidal GABAergic neurons and apical dendrites of pyramidal neurons located in layers 2-6 ( $\mathrm{Li}$ and Schwark, 1994; Prieto et al., 1994), receives considerable sensory inputs conveying presumably attention-related signals (Cauller and Kulics, 1991; Robinson and Petersen, 1992; Casagrande, 1994; Jones, 2001). It is proposed that layer 1 inputs can interact with sensory inputs arriving in layer 4 to elicit dendritic calcium-dependent action potentials (Larkum et al., 1999; Larkum and Zhu, 2002), which promote burst firing, crucial for relaying preferred information into higher-level cortical areas (Lisman, 1997). However, this dendritic coincident detection mechanism requires the concurrent arrival of sensory inputs in layers 1 and 4 (Larkum et al., 1999; Llinas et al., 2002), which is contradictory to the customary view that sensory inputs to layer 1 are relayed primarily by the secondary sensory ascending system, in which neurons respond to tactile stimuli and convey information sluggishly (Herkenham, 1979; Diamond et al., 1992; Ahissar et al., 2000). To determine exactly when the sensory signals arrive in layer 1 , it is necessary to examine the sensory-stimulus-evoked responses in layer

Received 0ct. 24, 2003; revised Dec. 11, 2003; accepted Dec. 11, 2003.

This work is supported in part by a University of Virginia Research and Development Award. J.J.Z. is an Alfred P. Sloan Fellow. We thank Drs. Z. Chu, F.-S. Lo, R. Malinow, E. Stern, R. Stornetta, and members of the Zhu laboratory for helpful comments and discussions and Dr. B. Sakmann for his support during the preliminary investigation.

Correspondence should be addressed to Dr. Julius Zhu, Department of Pharmacology, University of Virginia School of Medicine, 1300 Jefferson Park Avenue, Charlottesville, VA 22908. E-mail: jzzhu@virginia.edu.

DOI:10.1523/JNEUROSCI.4805-03.2004

Copyright $\odot 2004$ Society for Neuroscience $\quad$ 0270-6474/04/241272-08\$15.00/0
1 neurons. However, in part because of the technical difficulty, such an approach has so far succeeded in only one layer 1 neuron (Martin et al., 1989).

The same technical obstacle has delayed the characterization of receptive field properties of layer 1 neurons, although the properties have been well characterized in neurons located in other cortical layers using whole-cell in vivo recording techniques (Moore and Nelson, 1998; Zhu and Connors, 1999; Stern et al., 2001; Brecht and Sakmann, 2002). These studies have demonstrated that cortical neurons respond best to a brief deflection of one primary whisker, but typically $\sim 10$ surrounding whiskers also generate significant synaptic responses. In addition, the receptive fields of layer 2-6 neurons display the same acuity; the average responses in these neurons to the deflection of first- and second-order surrounding whiskers are $\sim 50 \%$ of those to the deflection of the primary and first-order surrounding whiskers, respectively. It remains to be determined whether layer 1 neurons have the same receptive field properties as neurons located in layers 2-6.

Approximately 100 years ago, Ramon y Cajal made the first series of observations on layer 1 neurons (Ramon y Cajal et al., 1988). Later studies have extended his work and identified two general classes of nonpyramidal neurons in layer 1: local circuit neurons (LCNs), which have a locally restricted axon, and deeper-layer-projecting neurons (DLPNs), which have a descending axon innervating deeper layers (Bradford et al., 1977; Marin-Padilla, 1990; Zhou and Hablitz, 1996b; Christophe et al., 2002; Chu et al., 2003; Gonchar and Burkhalter, 2003). Using a whole-cell in vivo recording technique that targets neurons in 
layer 1 and tuft dendrites of layer 5 pyramidal neurons in layers $1-2$, we studied the whisker-evoked synaptic responses in these neurons. We found that LCNs and DLPNs, as well as tuft dendrites of layer 5 pyramidal neurons, responded to a brief deflection of one primary whisker with a latency of $\sim 5-7 \mathrm{msec}$ and to 5-14 surrounding whiskers with longer latencies. In comparison with LCNs, DLPNs had a smaller receptive field with higher acuity and a shorter latency in response to the deflection of the primary whisker. In addition, the latency for primary whiskerevoked responses in tufts of layer 5 pyramidal neurons is shorter than that in their somata.

\section{Materials and Methods}

Animal preparation. As described previously (Zhu and Connors, 1999; Larkum and Zhu, 2002), adult rats ( $180-280 \mathrm{gm} ; n=107)$ were initially anesthetized by an intraperitoneal injection of pentobarbital sodium (60 $\mathrm{mg} / \mathrm{kg})$. Supplemental doses $(10 \mathrm{mg} / \mathrm{kg}$ ) of pentobarbital were given as needed to keep animals free from pain reflexes and in a state of slow-wave general anesthesia, as determined by monitoring the cortical electroencephalogram. All pressure points and incised tissues were infiltrated with lidocaine. Body temperature (rectal) was monitored and maintained within the normal range $\left(37.2 \pm 0.3^{\circ} \mathrm{C}\right)$. During the physiological investigation, the animals were placed in a stereotaxic frame. A hole $\sim 3 \times 4$ $\mathrm{mm}$ was opened above the right somatosensory cortex according to stereotaxic coordinates. The dura was opened before the electrode penetrations. To record more layer 1 neurons and tuft dendrites of layer 5 pyramidal neurons, patch electrodes were arranged to penetrate the barrel cortex at a sharp angle $\left(\sim 15-30^{\circ}\right)$ against the surface plane. The patch electrodes were advanced $\sim 500-700 \mu \mathrm{m}$ into the cortex. If no cell was encountered during one penetration, the electrode was withdrawn and moved to a different location to search cells again. In comparison with the traditional whole-cell in vivo recording method (Zhu and Connors, 1999; Larkum and Zhu, 2002), this approach increased the chance of encountering layer 1 neurons and tuft dendrites of layer 5 pyramidal neurons by $\sim 100 \%$. Typically, we were able to obtain stable recordings from one layer 1 neuron or the tuft dendrite of a layer 5 neuron after performing experiments on approximately four animals.

Electrophysiology. Whole-cell recordings were made blindly as described previously (Zhu and Connors, 1999; Larkum and Zhu, 2002). Long-taper patch electrodes were made from borosilicate tubing, and their resistances were 5-14 $\mathrm{M} \Omega$ when filled with standard intracellular solution containing the following (in $\mathrm{mM}$ ): 115 potassium gluconate, 10 HEPES, $2 \mathrm{MgCl}_{2}$, $2 \mathrm{MgATP}, 2 \mathrm{Na}_{2} \mathrm{ATP}, 0.3 \mathrm{GTP}$, and $20 \mathrm{KCl}$ and biocytin $0.25 \%, \mathrm{pH} 7.3$. The liquid junction potential was not corrected. To obtain whole-cell recordings, electrodes were advanced into the brain while pulsing with $0.1 \mathrm{nA}$ current steps of $200 \mathrm{msec}$ duration. Positive pressure (75-150 mbar) was constantly applied to the pipette while it was being advanced. A short pulse of high pressure (300-450 mbar) was applied intermittently to inject biocytin and stain cell debris along the penetration pathway. When a sudden increase in electrode resistance was evident, gentle suction was applied to obtain a seal resistance of $\geq 1 \mathrm{G} \Omega$. The patch of membranes was broken by applying more negative pressure to obtain a whole-cell configuration. All in vivo data were collected when the access resistance of the recording was $<50 \mathrm{M} \Omega$. An Axoclamp-2B amplifier (Axon Instruments, Foster City, CA) was used for intracellular recordings. The electrode capacitance compensation was made in discontinuous current-clamp mode with the head-stage output continuously monitored on a second oscilloscope.

Whisker stimulation. Single whiskers on the contralateral face were deflected briefly for a short distance $(40-200 \mu \mathrm{m})$ with a piezoelectric stimulator, placed adjacent to the whisker, and activated by single, brief voltage pulses [0.3-0.5 msec; 2-10 V; $0.25 \mathrm{~Hz}$ (cf. Dykes et al., 1977; Simons, 1983)]. To assess the receptive field size of layer 1 and layer 5 neurons, we examined their responses to a brief deflection of each of 27 mystacial vibrissas, from $A_{0}$ to $E_{5}$, in the contralateral face [whiskers $A_{5}$ and $\mathrm{B}_{5}$ were very small and were not stimulated, whereas whisker $\mathrm{E}_{0}$ is absent in the rat (Chapin and Lin, 1984)]. The receptive fields were examined at the resting membrane potential or at a slightly hyperpolar- ized potential, which was usually near the reversal potential of the IPSP; this minimized the effect of IPSPs on the initial EPSP. Because most cortical cells displayed high rates of spontaneous activity, 8-16 trials of whisker deflection were averaged. Unless stated otherwise, the latency for whisker-evoked EPSPs was measured at the onset of the averaged responses, whereas the latency and duration for the evoked action potentials were measured at their thresholds.

Histology. After recordings, a small block of tissue, including the recorded cell, was removed from the brain and immersion-fixed with $4 \%$ paraformaldehyde in $0.1 \mathrm{~m}$ phosphate buffer. The tissue blocks were later sectioned $250 \mu \mathrm{m}$ thick with a microslicer. Tissue sections were processed with the avidin-biotin-peroxidase method to reveal cell morphology. Cells were then drawn with the aid of a microscope equipped with a computerized reconstruction system (Neurolucida, Williston, VT). Only the data from the morphologically identified layer 1 and layer 5 neurons were included in this report. All results are reported as means \pm SEM. Statistical differences of the means were determined using the $t$ test, unless stated otherwise. The level of significance was set at $p<$ 0.05 .

\section{Results}

\section{Identification of layer 1 neurons recorded in vivo}

Layer 1 of the neocortex contains relatively sparse neurons and dendritic tuft branches of pyramidal neurons (Li and Schwark, 1994; Prieto et al., 1994). To increase the chance of encountering layer 1 neurons and tuft dendrites of pyramidal neurons, we arranged recording pipettes to penetrate the barrel cortex at a sharp angle $\left(\sim 15-30^{\circ}\right)$ against the surface plane and searched cells only in layers 1 and 2. Stable recordings, long enough to examine the full receptive field, were made from 22 putative layer 1 neurons. Among them, 15 neurons had relatively well recovered morphology; these neurons were classified as either LCNs $(n=9)$ or DLPNs $(n=6)$ and included in the analysis reported in this study (Figs. 1, 2).

All LCNs were multipolar, aspiny neurons, which were similar to neurogliaform neurons described previously (Kawaguchi, 1995; Hestrin and Armstrong, 1996; Gupta et al., 2000). These neurons had an axon ramifying densely within layer 1. DLPNs had a heterogeneous morphological appearance but all had axonal projections to deeper layers (Zhou and Hablitz, 1996b; Christophe et al., 2002; Chu et al., 2003). LCNs and DLPNs had the same resting membrane potential $(-69.5 \pm 1.8$ vs $-65.3 \pm$ $1.6 \mathrm{mV}$; $t$ test; $p=0.13)$, input resistance $(42.2 \pm 6.3$ vs $60.0 \pm$ $12.5 \mathrm{~m} \Omega ; p=0.18$ ) and generally fired relatively short duration action potentials $(1.6 \pm 0.1$ vs $1.9 \pm 0.3 \mathrm{msec} ; p=0.30)$. In comparison with young and juvenile layer 1 neurons (Hestrin and Armstrong, 1996; Zhou and Hablitz, 1996a), adult layer 1 neurons recorded in this study had a lower input resistance and a more hyperpolarized membrane potential, and they fired action potentials with shorter duration, which is consistent with the previous finding that postnatal maturation of intrinsic membrane properties of CNS neurons requires $\sim 4-6$ weeks ( $\mathrm{Zhu}$, 2000; Perreault et al., 2003). The intrinsic firing properties were also investigated in these two types of layer 1 neurons. In response to a prolonged near-threshold current pulse, LCNs displayed a delayed spiking pattern, whereas DLPNs started to fire action potentials at the onset of the pulse (Figs. $1 A, B, 2 A, B$ ), the same hallmark firing patterns of these neurons as shown previously in vitro (Chu et al., 2003).

\section{Whisker-evoked responses in layer 1 neurons}

We examined whisker-evoked responses in layer 1 neurons and found that both LCNs and DLPNs responded to a brief deflection of single whiskers on the contralateral face with robust synaptic potentials (Fig. 1C,D). The whisker-evoked responses consisted 

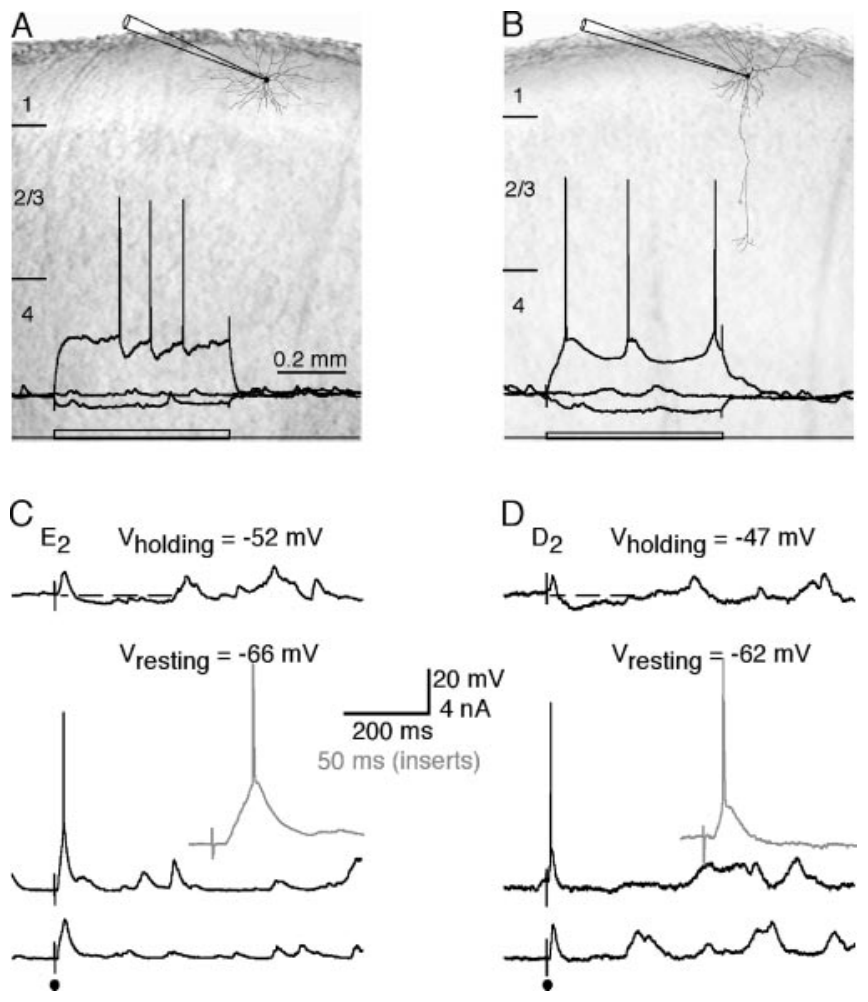

Figure 1. Whisker-evoked synaptic responses in layer 1 neurons. $A, B$, Neurolucida reconstruction of an LCN and a DLPN in layer 1. Recording traces show responses of the LCN and DLPN to hyperpolarizing and depolarizing current step injections. C, D, Whisker-evoked responses of the LCN and DLPN at different membrane potentials. Insets show the evoked action potentials at an expanded time scale (gray traces). The recording traces were single trials evoked by a brief deflection of primary whiskers.

of an initial EPSP with short latency followed by several PSPs during the next $\sim 800 \mathrm{msec}$. When the EPSPs were large enough, they triggered action potentials. The whisker-evoked responses included both EPSP and IPSP components. The IPSPs typically had very small amplitudes near resting potential but were significantly larger when the cells were depolarized.

Both LCNs and DLPNs responded best to one primary whisker that elicited the largest initial EPSP with the shortest latency. In addition, 5-14 surrounding whiskers also generated smaller initial EPSPs with longer latencies (Fig. 2C-F). On average, DLPNs had smaller receptive fields (defined as the number of whiskers that evoked an initial EPSP) than LCNs (8.2 $\pm 0.7, n=$ 6 vs $12.9 \pm 0.8, n=9 ; p<0.005)$. In addition, the receptive field of DLPNs exhibited acuity higher than that of LCNs (Fig. $3 A, B$ ). Namely, DLPNs had the same (or slightly larger) responses to the deflection of the primary whiskers but significantly smaller responses to the deflection of first- and second-order surrounding whiskers.

Remarkably, both LCNs and DLPNs responded to the primary whisker with a short latency (Figs. 2, 3); the primary whisker-evoked EPSPs started as early as $\sim 5-7$ msec after stimuli $(n=15)$. Interestingly, the latency was significantly shorter in DLPNs than in LCNs (Fig. 3C). Consistent with this, the peak latency of the primary-whisker-evoked initial EPSPs was shorter in DLPNs than in LCN $(10.8 \pm 0.8 \mathrm{msec}, n=6$ vs $14.9 \pm 0.7$ msec, $n=9$; $p<0.005)$ and primary whisker-evoked action potentials fired earlier in DLPNs than in LCNs (Figs. 1C,D, 3D). Overall, the latencies for primary whisker-evoked EPSPs in layer 1 neurons were too short for the response to be relayed by layer 4
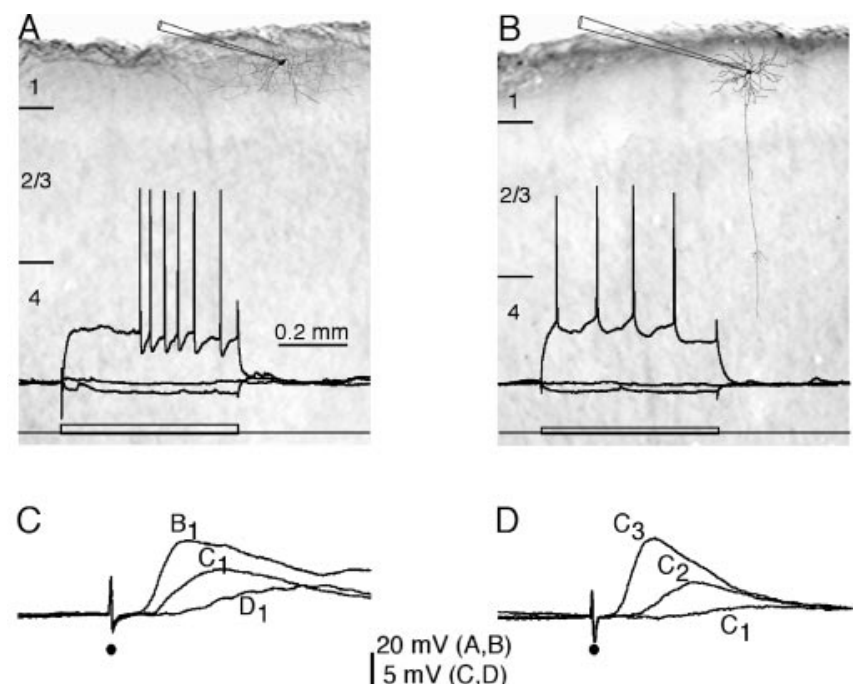

$200 \mathrm{~ms}(\mathrm{~A}, \mathrm{~B}) 4 \mathrm{nA}$

$20 \mathrm{mV}(\mathrm{A}, \mathrm{B})$ $20 \mathrm{~ms}(\mathrm{C}, \mathrm{D})$
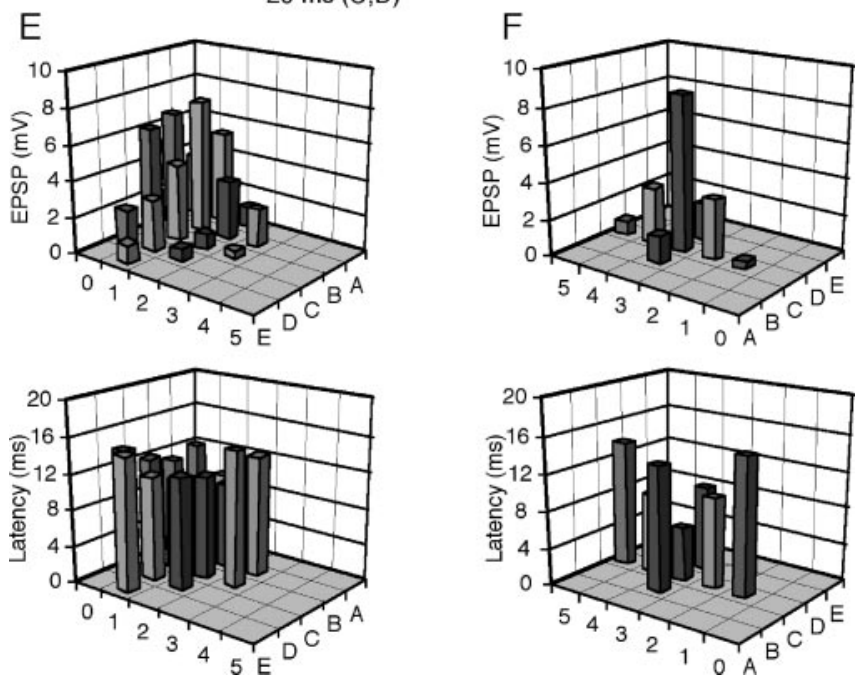

Figure 2. Receptive fields of whisker-evoked synaptic responses of layer 1 neurons. $A, B$ Neurolucida reconstruction of an LCN and a DLPN in layer 1. C, D, Average responses of the LCN and DLPN to a brief deflection of the primary whisker, a first-order surrounding whisker, and a second-order surrounding whisker. Note that the primary whiskers of the $L C N$ and DPLN were $B_{1}$ and $C_{3}$ respectively. $E, F$, Amplitudes and latency of the initial, short-latency EPSPs evoked by brief deflections of single whiskers from $A_{0}-E_{5}$ in the same $L C N$ and DLPN.

neurons, in which the latencies for primary whisker-evoked EPSPs were reported to be $5-8 \mathrm{msec}$ (Moore and Nelson, 1998; Zhu and Connors, 1999; Brecht and Sakmann, 2002). These results indicate that sensory inputs arrive in layer 1 concomitantly with those arriving in layer 4 and they must be relayed at least in part by fast, direct ascending pathways.

\section{Whisker-evoked responses in the soma and tuft dendrite of} layer 5 pyramidal neurons

Layer 5 pyramidal neurons receive and integrate sensory inputs from both layer 1 and layer 4 (Reyes, 2001; Hausser and Mel, 2003). The tuft dendrites of these neurons, in which layer 1 inputs are first received, are electrotonically isolated from the soma, where layer 4 inputs received directly and/or indirectly are integrated (Zhu, 2000; Larkum et al., 2001; Larkum and Zhu, 2002). To compare directly the timing of sensory inputs arriving in layers 1 and 4 in the same neurons, we recorded the whisker-evoked responses in the soma $(n=7)$ and dendritic tuft $(n=7)$ of layer 

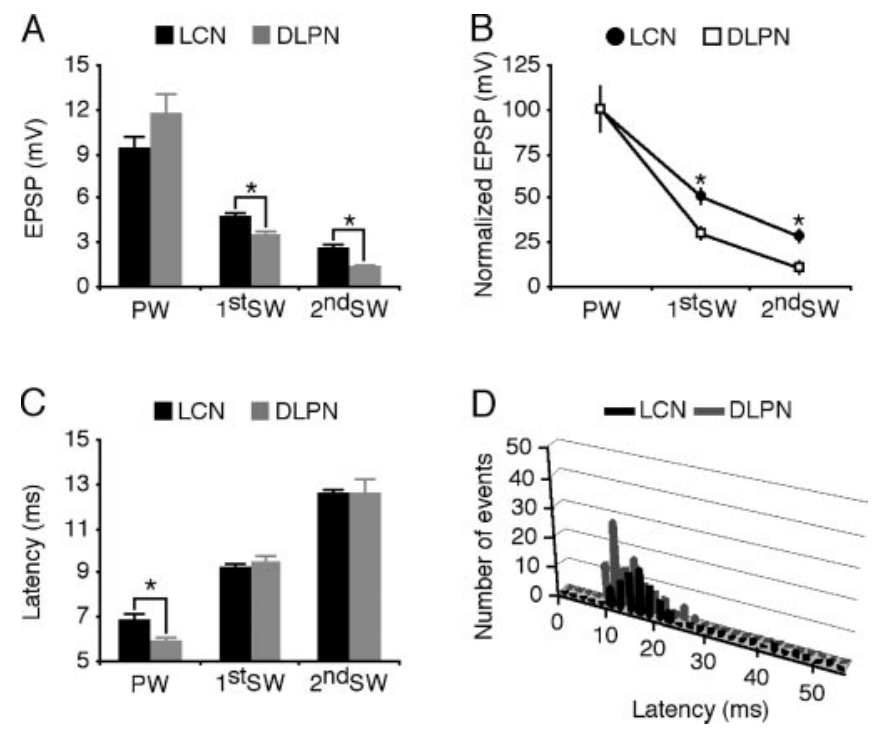

Figure 3. Receptive fields of whisker-evoked synaptic responses of layer 1 neurons. $A$, Histograms show average amplitudes of the initial, short-latency EPSPs in LCNs and DLPNs $(9.3 \pm$ 1.0 vs $11.5 \pm 1.5 \mathrm{mV}, p=0.21$ for PW; $4.7 \pm 0.3$ vs $3.3 \pm 0.4 \mathrm{mV}, p<0.05$ for first $S W ; 2.6 \pm$ 0.2 vs $1.2 \pm 0.3 \mathrm{mV}, p<0.005$ for second SW). $B$, Plots of average acuities of receptive fields of LCNs and DLPNs $(50.5 \pm 3.7$ vs $29.9 \pm 3.2 \%, p<0.005$ for first SW; $27.5 \pm 2.3$ vs $10.3 \pm$ $2.3 \%, p<0.005$ for second SW). EPSP amplitudes and SEs were normalized to average values from primary whiskers in plots. $C$, Histograms of average latencies of the initial, short-latency EPSPs of LCNs and DLPNs ( $6.8 \pm 0.3$ vs $5.9 \pm 0.2 \mathrm{msec}, p<0.05$ for PW; $9.2 \pm 0.2$ vs $9.4 \pm$ $0.3 \mathrm{msec}, p=0.58$ for first SW; $12.5 \pm 0.2$ vs $12.5 \pm 0.7 \mathrm{msec}, p=0.97$ for second SW). $D$, Distributions of latencies for primary whisker-evoked action potentials in LCNs ( $n=72$ from six neurons) and DLPNs ( $n=92$ from five neurons). The shortest latencies for primary-whiskerevoked action potentials were significantly different between LCNs and DLPNs (13.1 \pm 1.5 msec, $n=6$ vs $9.7 \pm 1.0 \mathrm{msec}, n=5 ; p<0.01$ ).

5 pyramidal neurons (Figs. 4,5 ). As reported in previous in vitro and in vivo studies (Zhu, 2000; Larkum and Zhu, 2002), the dendritic tuft of layer 5 pyramidal neurons had a more depolarized resting membrane potential than the soma $(-55.4 \pm 2.9$ vs $-66.4 \pm 1.3 \mathrm{mV} ; t$ test; $p<0.001)$, although they had the same input resistance $(22.0 \pm 1.9$ vs $28.0 \pm 1.1 \mathrm{~m} \Omega ; p=0.08)$.

A brief deflection of single whiskers evoked a short-latency EPSP followed by a fast IPSP and several delayed PSPs in the soma and tuft of layer 5 pyramidal neurons (Figs. $4 B, 5 B$ ). When the EPSPs were large enough, they triggered fast sodium-dependent action potentials in the soma, and slow or complex calciumdependent action potentials in the tuft (cf. Larkum and Zhu, 2002). Interestingly, the complex action potentials in the tuft often appeared to rise from the decay phase of the initial EPSPs (Fig. $5 B$, inset), suggesting that these complex action potentials were generated by the interaction of the axonal and dendritic action potential initiation zones (Larkum et al., 1999; Larkum and $\mathrm{Zhu}, 2002$ ). The soma and tuft of layer 5 pyramidal neurons had the same size receptive fields including 9-14 whiskers $(11.1 \pm 0.6, n=7$ vs $11.4 \pm 0.6, n=7 ; p=0.75)$ (Figs. $4 D, 5 D)$. The whisker-evoked responses were larger in the soma than those in the tuft, but the acuity of their receptive fields was the same (Fig. 6A,B).

Notably, the latency of the initial EPSP for the primary whisker in the tuft of layer 5 pyramidal neurons was $\sim 5-7 \mathrm{msec}(n=$ 7 ), shorter than that in the soma $(\sim 6.5-8.5 \mathrm{msec} ; n=7)$ (Figs. $4 B, 5 B, 6 C)$. In correspondence, the peak latency of the primarywhisker evoked initial EPSPs was shorter in the tuft than in the soma $(12.1 \pm 0.9 \mathrm{msec}, n=7$ vs $16.1 \pm 1.1 \mathrm{msec}, n=7 ; p<0.05)$. In addition, the slow action potentials generated in the tuft had a
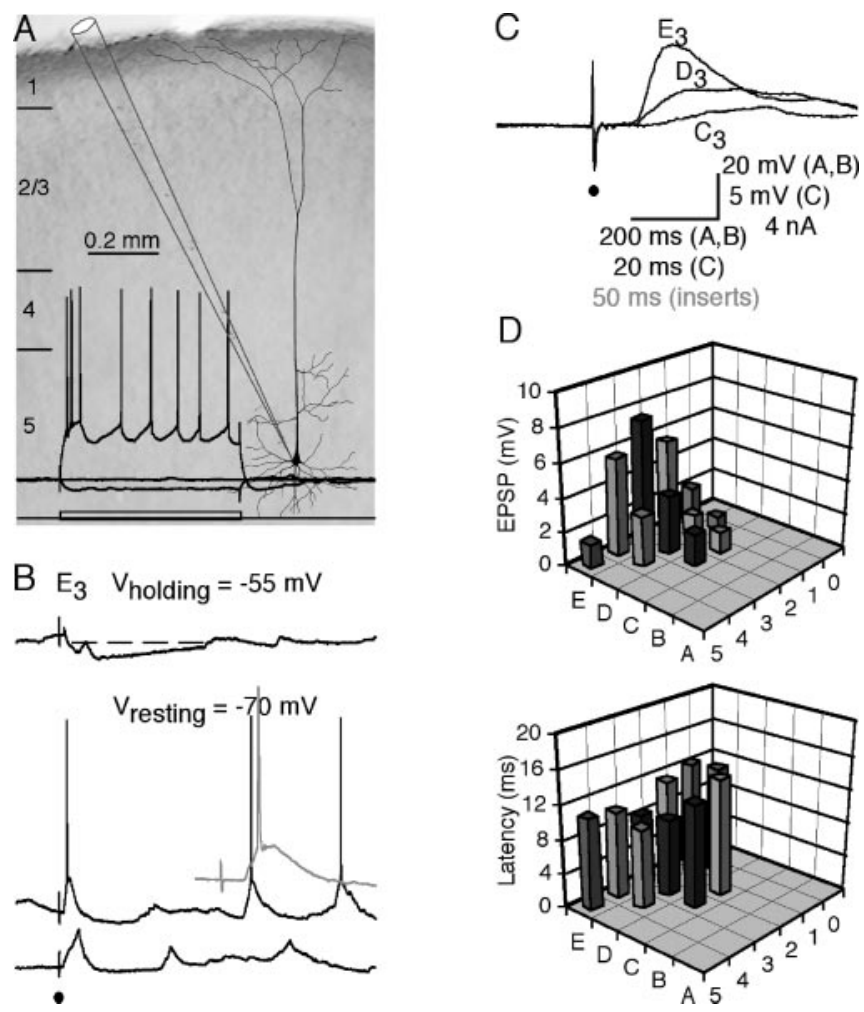

Figure 4. Receptive field of whisker-evoked synaptic responses of a layer 5 pyramidal neuron recorded at the soma. $A$, Neurolucida reconstruction of a layer 5 pyramidal neuron shows that the recording was made at the soma. Recording traces show the responses of the neuron to hyperpolarizing and depolarizing current step injections. $B$, Whisker-evoked responses of the neuron at different membrane potentials. The inset shows the evoked fast action potential at an expanded time scale (gray trace). The recording traces were single trials evoked by a brief deflection of the primary whisker, $E_{3}$. C, Average responses of the neuron to a brief deflection of the primary whisker, a first-order surrounding whisker and a second-order surrounding whisker. $D$, Amplitudes and latency of the initial, short latency EPSPs evoked by brief deflections of single whiskers from $A_{0}-E_{5}$ in the same neuron.

shorter latency than the fast action potentials initiated in the soma (Fig. 6D). The complex action potentials in the dendritic tuft had the longest latency (Fig. 6D), congruous with the notion that they were initiated in the soma (Larkum and Zhu, 2002). These results indicate that sensory inputs arrive earlier in the tuft of layer 5 pyramidal neurons via layer 1 than the soma via layer 4 and reinforce the idea that sensory information arrives in layer 1 via fast ascending pathways.

\section{Discussion}

Our in vivo experiments demonstrate that adult neurons in layer 1 of the barrel cortex display two general classes of intrinsic physiology that are similar to those of juvenile layer 1 neurons recorded in vitro from the rat neocortex. Both LCNs and DLPNs in layer 1 respond best to one primary whisker with a short latency of $5-7$ msec, but typically 5-14 surrounding whiskers also show significant synaptic responses with a longer latency of 8-12 msec. On average, DLPNs have a smaller receptive field with higher acuity compared with LCNs. In addition, our results show that both the dendritic tuft and soma of layer 5 pyramidal neurons respond to multiple whiskers. They have a receptive field with similar properties, although the latency for primary whiskerevoked initial EPSPs in the tuft of layer 5 pyramidal neurons is $\sim 5-7 \mathrm{msec}, \sim 1 \mathrm{msec}$ shorter than that in the soma. Thus, ascending sensory inputs arrive in layer 1 at approximately the 


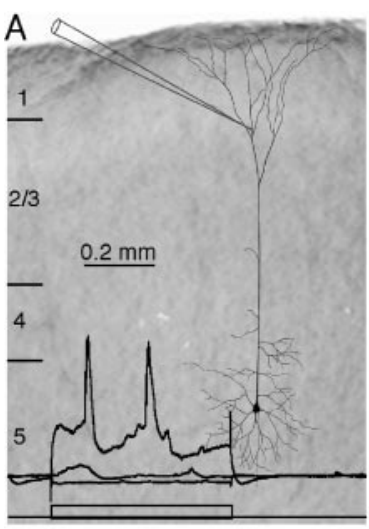

B $D_{1} \quad V_{\text {holding }}=-42 \mathrm{mV}$

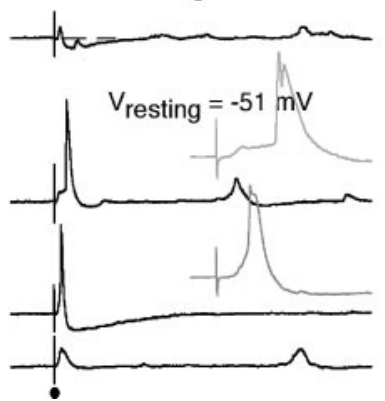

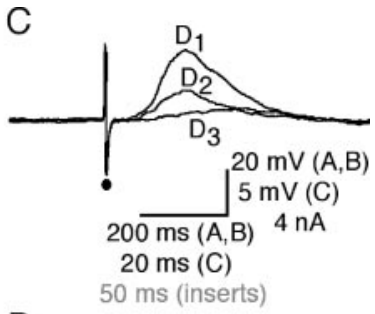

D
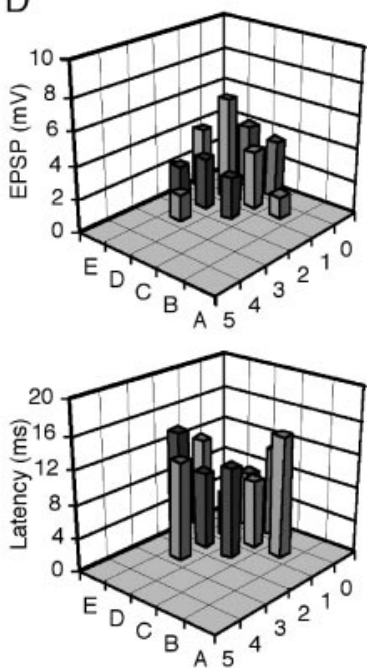

Figure 5. Receptive field of whisker-evoked synaptic responses of a layer 5 pyramidal neuron recorded at the dendritic tuft. $A$, Neurolucida reconstruction of a layer 5 pyramidal neuron shows that the recording was made at the dendritic tuft. Recording traces show the responses of the tuft to hyperpolarizing and depolarizing current step injections. $B$, Whisker-evoked responses of the tuft at different membrane potentials. Insets show the evoked slow and complex action potentials at an expanded time scale (gray traces). The recording traces were single trials evoked by a brief deflection of the primary whisker, $D_{1}$. C, Average responses of the tuft to a brief deflection of the primary whisker, a first-order surrounding whisker, and a second-order surrounding whisker. D, Amplitudes and latency of the initial, short-latency EPSPs evoked by brief deflections of single whiskers from $A_{0}-E_{5}$ in the same tuft.

same time as those that arrive in layer 4, which provides a neural basis for the coincident detection of salient sensory information by layer 5 pyramidal neurons.

\section{Intrinsic properties of layer 1 neurons}

As with previous in vitro studies (Hestrin and Armstrong, 1996; Chu et al., 2003), LCNs and DLPNs recorded in vivo display distinct intrinsic firing patterns. In particular, LCNs fire delayed action potentials in response to a near-threshold current pulse, which may contribute to the relatively slow initiation of whiskerevoked action potentials in these neurons (Fig. 3D). Because LCNs form GABAergic synapses on DLPNs (Chu et al., 2003), the relatively slow arrival of sensory inputs (Fig. $3 C$ ) and delayed firing in LCNs gives an adequate amount of time for DLPNs to integrate fast ascending sensory inputs and initiate their action potentials.

\section{Receptive field of layer 1 neurons}

The receptive field structure of cortical neurons is somewhat controversial because some early extracellular single-unit recording studies have reported small, often single-whisker receptive fields, whereas others have shown multiple-whisker receptive fields (Simons, 1983; Armstrong-James and Fox, 1987; Ghazanfar and Nicolelis, 1999; Fox et al., 2003). Intracellular recordings with sharp electrodes, and more recently whole-cell recordings with
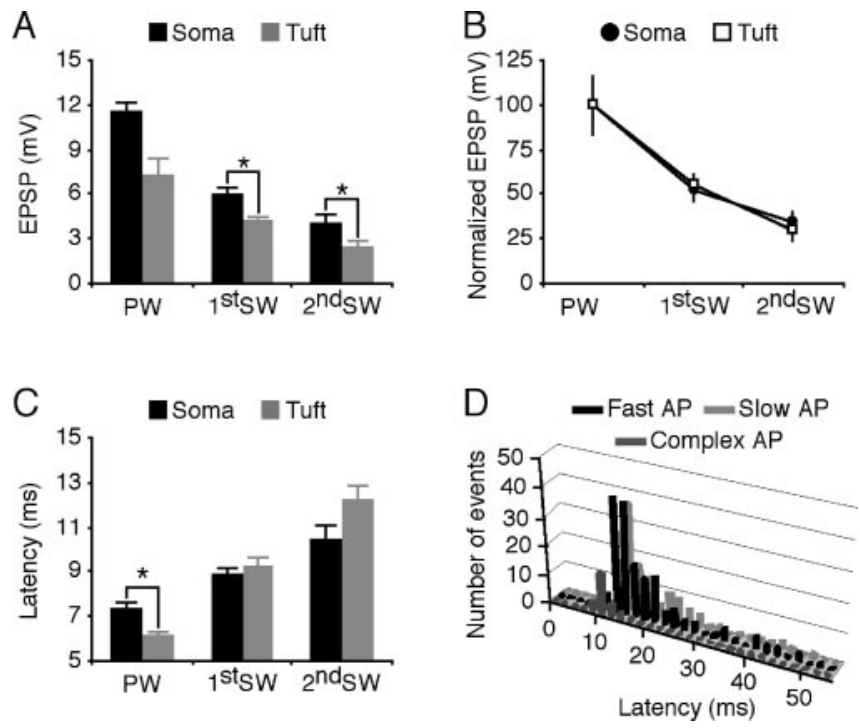

Figure 6. Receptive fields of whisker-evoked synaptic responses of the tuft and soma of layer 5 pyramidal neurons. $A$, Histograms show average amplitudes of the initial, short-latency EPSPS in the soma and tuft of layer 5 pyramidal neurons $(10.4 \pm 1.2 \mathrm{vs} 7.2 \pm 1.2 \mathrm{mV}, p=0.08$ for PW; $5.8 \pm 0.6$ vs $4.0 \pm 0.4 \mathrm{mV}, p<0.05$ for first SW; $3.7 \pm 0.6$ vs $2.1 \pm 0.4 \mathrm{mV}, p<0.05$ for second SW). $B$, Plots of average acuities of receptive fields of the soma and tuft of layer 5 pyramidal neurons $(55.6 \pm 5.4$ vs $55.8 \pm 5.9 \%, p=0.99$ for first SW; $35.7 \pm 6.2$ vs $29.1 \pm$ $5.1 \%, p=0.42$ for second SW). EPSP amplitudes and SEs were normalized to average values from primary whiskers in plots. C, Histograms of average latencies of the initial, short-latency EPSPs of the soma and tuft of layer 5 pyramidal neurons ( $7.2 \pm 0.4$ vs $6.0 \pm 0.3 \mathrm{msec}, p<0.05$ for PW; $8.8 \pm 0.4$ vs $9.2 \pm 0.5 \mathrm{msec}, p=0.48$ for first SW; $10.4 \pm 0.7$ vs $12.1 \pm 0.7 \mathrm{msec}, p=$ 0.27 for second SW). D, Distributions of latencies for primary whisker-evoked action potentials in the soma ( $n=162$ fast action potentials from seven neurons) and tuft ( $n=24$ slow action potentials from four neurons and $n=113$ complex action potentials from six neurons) of layer 5 pyramidal neurons. The shortest latencies for primary-whisker-evoked fast action potentials in the soma were $13.9 \pm 0.8 \mathrm{msec}(n=7)$, whereas for slow and complex action potentials in the tuft, the latencies were $11.2 \pm 1.3(n=4)$ and $16.4 \pm 0.7 \mathrm{msec}(n=6)$, respectively. The differences between the latencies for slow and complex action potentials $(n=4$; paired $t$ test; $p<0.05$ ) and between those for fast action potentials and complex action potentials ( $p<$ $0.05)$ were significant.

patch pipettes, demonstrate that cortical neurons located in layers 2-6 have a large subthreshold receptive field including $\sim 10$ whiskers (Carvell and Simons, 1988; Ito, 1992; Moore and Nelson, 1998; Zhu and Connors, 1999; Stern et al., 2001; Brecht and Sakmann, 2002; Brecht et al., 2003; Petersen et al., 2003). It is unclear whether layer 1 neurons have the same large receptive field. Whole-cell recordings from layer 1 neurons in this study reveal that layer 1 neurons have a large receptive field consisting of 6-15 whiskers. However, the receptive field properties are different in the two types of layer 1 neurons. Although LCNs have a larger receptive field than DLPNs, the acuity of the receptive fields is higher in DLPNs. Because LCNs have a dense local axon extending over a large horizontal area in layer 1 (Zhou and Hablitz, 1996b; Christophe et al., 2002; Chu et al., 2003), they may convert multiple whisker inputs into GABAergic outputs to the distal dendrite of a large number of pyramidal neurons in different barrels. DLPNs have only a few short axonal branches in layer 1 but a long axon projecting into deeper layers, where it gives rise to several collaterals in a vertical area presumably belonging to a single barrel (Zhou and Hablitz, 1996b; Christophe et al., 2002; Chu et al., 2003). Thus, DLPNs may transfer sensory inputs with precise whisker location coding into a small number of neurons in the same barrel. 


\section{Timing of ascending sensory inputs arriving in layer 1}

It is believed that ascending sensory systems contain at least two general types of thalamocortical relay pathways: primary or specific pathways (e.g., lemniscal pathways) relaying sensory information to cortical layer 4 , and secondary or nonspecific pathways (e.g., paralemniscal pathways) relaying presumably salient, novel and/or attention-related information to cortical layer 1 (Robinson and Petersen, 1992; Casagrande, 1994; Jones, 2001). A number of studies have reported that thalamocortical neurons in secondary ascending sensory pathways project their axon to layer 1 (Herkenham, 1979, 1980; Aumann et al., 1998; Huang and Winer, 2000; Mitchell and Cauller, 2001) and unlike those in primary sensory ascending pathways, these neurons show poor receptive fields, labile latencies, and strong dependence on modulatory inputs (Sur and Sherman, 1982; Norton et al., 1988; Diamond et al., 1992; Zhu and Lo, 1998; Ahissar et al., 2000). Surprisingly, whisker stimuli evoke robust synaptic responses in layer 1 neurons and tuft dendrites of layer 5 pyramidal neurons recorded in vivo with a latency of $\sim 5-7 \mathrm{msec}$. Because of the long latency for sensory inputs to reach the cortex via the secondary ascending pathway (Diamond et al., 1992; Ahissar et al., 2000; Llinas et al., 2002) and for cortical layer 4 neurons to reach firing threshold (Moore and Nelson, 1998; Zhu and Connors, 1999; Brecht and Sakmann, 2002), the substantial proportion of the primary whisker-evoked responses must be mediated by fast direct thalamocortical pathways. Indeed, a growing body of evidence suggests that a significant number of thalamocortical neurons located in specific thalamic nuclei project their axons to layer 1 (Penny et al., 1982; Landry et al., 1987; Rausell and Jones, 1991; Hendry and Yoshioka, 1994; Huang and Winer, 2000).

Because ascending sensory inputs arrive in layer 4 neurons with a short latency of $\sim 5-8 \mathrm{msec}$ (Moore and Nelson, 1998; Zhu and Connors, 1999; Brecht and Sakmann, 2002), our results indicate that ascending sensory information arrives in layers 1 and 4 concomitantly. This result is of functional significance because the threshold for initiation of dendritic calcium action potentials is significantly lowered when layers 1 and 4 inputs arrive concurrently within a window of a few milliseconds (Larkum et al., 1999). Because dendritic calcium action potentials promote burst firing important for nonlinearly amplifying synaptic responses (Larkum et al., 1999; Zhu, 2000) and increasing synaptic transmission reliability (Lisman, 1997; Williams and Stuart, 1999), layer 5 pyramidal neurons, the main output neurons in the cortex, may use this dendritic coincident detection mechanism to select, amplify, and relay salient sensory information to higherlevel cortical areas (Kamondi et al., 1998; Helmchen et al., 1999; Larkum and Zhu, 2002; Berger and Luscher, 2003).

\section{Neuronal circuitry involved in processing layer 1 sensory inputs}

How ascending sensory inputs arriving in layer 4 are integrated in the cortex has been extensively studied in the past several decades (Mountcastle, 1957; Hubel and Wiesel, 1962). A complex cortical circuitry involved in processing the inputs has now been dissected (for recent reviews, see Ferster and Miller, 2000; Ghazanfar and Nicolelis, 2001; Fox, 2002). In contrast, the layer 1 neuronrelated circuits have only recently become the subjects of investigation in vitro (Christophe et al., 2002; Radnikow et al., 2002; Chu et al., 2003; Soda et al., 2003). In the intact brain, both layer 1 neurons and tuft dendrites of layer 5 pyramidal neurons receive and integrate sensory inputs from multiple whiskers. Given these in vivo results, as well as the available in vitro data, it appears that layer 1 neurons and apical dendrites of pyramidal neurons form a neuronal circuitry ideal for regulating the initiation of dendritic action potentials and thus selecting and amplifying salient sensory inputs.

A striking feature of this circuitry is that the anatomical and physiological properties of layer 1 neurons, including intrinsic membrane properties, receptive field, morphology, and arrival timing of sensory inputs, fit well with their roles. For example, layer 1 neurons synapse directly on the dendritic tufts of pyramidal neurons (Chu et al., 2003) and fire action potentials shortly after whisker stimulation. They provide fast GABAergic inputs, which facilitate the initiation of dendritic action potentials by acting as a depolarizing force and by reducing the dendritic membrane time constant, thus promoting coupling of dendritic regenerative currents (Larkum and Zhu, 2002; Berger and Luscher, 2003). Layer 1 neurons receive sensory inputs from multiple whiskers. In particular, LCNs have a large receptive field with low acuity and an extended axonal branching field in layer 1, which allows these neurons to be activated by multiple whiskers and to promote the initiation of action potentials in distal dendrites of a large number of pyramidal neurons. In addition, these neurons are intensively interconnected by electrical coupling (Chu et al., 2003), which may synchronize the excitation in postsynaptic tuft dendrites (Beierlein et al., 2000; Galarreta and Hestrin, 2001; Szabadics et al., 2001). However, the dendritic excitability of layer 5 pyramidal neurons is subject to the control of layer $2 / 3$ interneurons, whose inhibition can "veto" the initiation of dendritic action potentials (Larkum et al., 1999). DLPNs may function to relieve this inhibition in a selective set of pyramidal neurons, for three reasons. First, DLPNs have an axon projecting to layer 2/3, and excitation of layer 1 neurons inhibits selectively layer $2 / 3$ interneurons (Cauller and Connors, 1994; Christophe et al., 2002). Second, DLPNs receive the fastest-ascending sensory inputs; they should be able to suppress firing in layer $2 / 3$ interneurons before the initiation of dendritic action potentials in layer 5 pyramidal neurons without themselves being first inhibited by LCNs. Third, DLPNs have a high-acuity receptive field. It is expected that their suprathreshold field will be much smaller (Anderson et al., 2000; Petersen et al., 2003). Namely, only tactile inputs from single or a very small number of whiskers will be strong enough to trigger action potentials in these neurons. Therefore, the activity of DLPNs will code the precise location of tactile stimuli and disinhibit only a small selective population of pyramidal neurons, important for generating a selective "attention window" and discriminately amplifying salient sensory information (Larkum et al., 1999; Larkum and Zhu, 2002). Thus, layer 1 neurons and tuft dendrites of pyramidal neurons together seem to construct an efficient neuronal circuitry for extracting and amplifying salient sensory information arriving in the different cortical layers. Given the functional significance (Cauller and Kulics, 1991; Robinson and Petersen, 1992; Casagrande, 1994; Larkum et al., 1999; Jones, 2001; Larkum and Zhu, 2002) and rapid arrival of sensory inputs in layer 1 , it is important to determine how sensory inputs arriving in layer 4 are processed when animals are awake, during which layer 1 inputs are dramatically enhanced (Cauller and Kulics, 1991).

\section{References}

Ahissar E, Sosnik R, Haidarliu S (2000) Transformation from temporal to rate coding in a somatosensory thalamocortical pathway. Nature 406:302-306.

Anderson JS, Lampl I, Gillespie DC, Ferster D (2000) The contribution of noise to contrast invariance of orientation tuning in cat visual cortex. Science 290:1968-1972. 
Armstrong-James M, Fox K (1987) Spatiotemporal convergence and divergence in the rat S1 "barrel" cortex. J Comp Neurol 263:265-281.

Aumann TD, Ivanusic J, Horne MK (1998) Arborisation and termination of single motor thalamocortical axons in the rat. J Comp Neurol 396:121-130.

Beierlein M, Gibson JR, Connors BW (2000) A network of electrically coupled interneurons drives synchronized inhibition in neocortex. Nat Neurosci 3:904-910.

Berger T, Luscher HR (2003) Timing and precision of spike initiation in layer $\mathrm{V}$ pyramidal cells of the rat somatosensory cortex. Cereb Cortex 13:274-281.

Bradford R, Parnavelas JG, Lieberman AR (1977) Neurons in layer I of the developing occipital cortex of the rat. J Comp Neurol 176:121-132.

Brecht M, Roth A, Sakmann B (2003) Dynamic receptive fields of reconstructed pyramidal cells in layers 3 and 2 of rat somatosensory barrel cortex. J Physiol (Lond) 553:243-265.

Brecht M, Sakmann B (2002) Dynamic representation of whisker deflection by synaptic potentials in spiny stellate and pyramidal cells in the barrels and septa of layer 4 rat somatosensory cortex. J Physiol (Lond) 543:49-70.

Carvell GE, Simons DJ (1988) Membrane potential changes in rat SmI cortical neurons evoked by controlled stimulation of mystacial vibrissae. Brain Res 448:186-191.

Casagrande VA (1994) A third parallel visual pathway to primate area V1. Trends Neurosci 17:305-310.

Cauller LJ, Connors BW (1994) Synaptic physiology of horizontal afferents to layer I in slices of rat SI neocortex. J Neurosci 14:751-762.

Cauller LJ, Kulics AT (1991) The neural basis of the behaviorally relevant $\mathrm{N} 1$ component of the somatosensory-evoked potential in SI cortex of awake monkeys: evidence that backward cortical projections signal conscious touch sensation. Exp Brain Res 84:607-619.

Chapin JK, Lin CS (1984) Mapping the body representation in the SI cortex of anesthetized and awake rats. J Comp Neurol 229:199-213.

Christophe E, Roebuck A, Staiger JF, Lavery DJ, Charpak S, Audinat E (2002) Two types of nicotinic receptors mediate an excitation of neocortical layer I interneurons. J Neurophysiol 88:1318-1327.

Chu Z, Galarreta M, Hestrin S (2003) Synaptic interactions of late-spiking neocortical neurons in layer 1. J Neurosci 23:96-102.

Diamond ME, Armstrong-James M, Budway MJ, Ebner FF (1992) Somatic sensory responses in the rostral sector of the posterior group (POm) and in the ventral posterior medial nucleus (VPM) of the rat thalamus: dependence on the barrel field cortex. J Comp Neurol 319:66-84.

Dykes RW, Dudar JD, Tanji DG, Publicover NG (1977) Somatotopic projections of mystacial vibrissae on cerebral cortex of cats. J Neurophysiol 40:997-1014.

Ferster D, Miller KD (2000) Neural mechanisms of orientation selectivity in the visual cortex. Annu Rev Neurosci 23:441-471.

Fox K (2002) Anatomical pathways and molecular mechanisms for plasticity in the barrel cortex. Neuroscience 111:799-814.

Fox K, Wright N, Wallace H, Glazewski S (2003) The origin of cortical surround receptive fields studied in the barrel cortex. J Neurosci 23:8380-8391.

Galarreta M, Hestrin S (2001) Spike transmission and synchrony detection in networks of GABAergic interneurons. Science 292:2295-2299.

Ghazanfar AA, Nicolelis MA (1999) Spatiotemporal properties of layer V neurons of the rat primary somatosensory cortex. Cereb Cortex 9:348-361.

Ghazanfar AA, Nicolelis MA (2001) Feature article: the structure and function of dynamic cortical and thalamic receptive fields. Cereb Cortex 11:183-193.

Gonchar Y, Burkhalter A (2003) Distinct GABAergic targets of feedforward and feedback connections between lower and higher areas of rat visual cortex. J Neurosci 23:10904-10912.

Gupta A, Wang Y, Markram H (2000) Organizing principles for a diversity of GABAergic interneurons and synapses in the neocortex. Science 287:273-278.

Hausser M, Mel B (2003) Dendrites: bug or feature? Curr Opin Neurobiol 13:372-383.

Helmchen F, Svoboda K, Denk W, Tank DW (1999) In vivo dendritic calcium dynamics in deep-layer cortical pyramidal neurons. Nat Neurosci 2:989-996.

Hendry SH, Yoshioka T (1994) A neurochemically distinct third channel in the macaque dorsal lateral geniculate nucleus. Science 264:575-577.
Herkenham M (1979) The afferent and efferent connections of the ventromedial thalamic nucleus in the rat. J Comp Neurol 183:487-517.

Herkenham M (1980) Laminar organization of thalamic projections to the rat neocortex. Science 207:532-535.

Hestrin S, Armstrong WE (1996) Morphology and physiology of cortical neurons in layer I. J Neurosci 16:5290-5300.

Huang CL, Winer JA (2000) Auditory thalamocortical projections in the cat: laminar and areal patterns of input. J Comp Neurol 427:302-331.

Hubel DH, Wiesel TN (1962) Receptive fields, binocular interaction and functional architecture in the cat's visual cortex. J Physiol (Lond) 148:106-154.

Ito M (1992) Simultaneous visualization of cortical barrels and horseradish peroxidase-injected layer $5 \mathrm{~b}$ vibrissa neurones in the rat. J Physiol (Lond) 454:247-265.

Jones EG (2001) The thalamic matrix and thalamocortical synchrony. Trends Neurosci 24:595-601.

Kamondi A, Acsady L, Buzsaki G (1998) Dendritic spikes are enhanced by cooperative network activity in the intact hippocampus. J Neurosci 18:3919-3928.

Kawaguchi Y (1995) Physiological subgroups of nonpyramidal cells with specific morphological characteristics in layer II/III of rat frontal cortex. J Neurosci 15:2638-2655.

Landry P, Diadori P, Leclerc S, Dykes RW (1987) Morphological and electrophysiological characteristics of somatosensory thalamocortical axons studied with intra-axonal staining and recording in the cat. Exp Brain Res 65:317-330.

Larkum ME, Zhu JJ (2002) Signaling of layer 1 and whisker-evoked $\mathrm{Ca}^{2+}$ and $\mathrm{Na}^{+}$action potentials in distal and terminal dendrites of rat neocortical pyramidal neurons in vitro and in vivo. J Neurosci 22:6991-7005.

Larkum ME, Zhu JJ, Sakmann B (1999) A new cellular mechanism for coupling inputs arriving at different cortical layers. Nature 398:338-341.

Larkum ME, Zhu JJ, Sakmann B (2001) Dendritic mechanisms underlying the coupling of the dendritic with the axonal action potential initiation zone of adult rat layer 5 pyramidal neurons. J Physiol (Lond) 533:447-466.

Li J, Schwark HD (1994) Distribution and proportions of GABAimmunoreactive neurons in cat primary somatosensory cortex. J Comp Neurol 343:353-361.

Lisman JE (1997) Bursts as a unit of neural information: making unreliable synapses reliable. Trends Neurosci 20:38-43.

Llinas RR, Leznik E, Urbano FJ (2002) Temporal binding via cortical coincidence detection of specific and nonspecific thalamocortical inputs: a voltage-dependent dye-imaging study in mouse brain slices. Proc Natl Acad Sci USA 99:449-454.

Marin-Padilla M (1990) Three-dimensional structural organization of layer I of the human cerebral cortex: a Golgi study. J Comp Neurol 299:89-105.

Martin KA, Friedlander MJ, Alones V (1989) Physiological, morphological, and cytochemical characteristics of a layer 1 neuron in cat striate cortex. J Comp Neurol 282:404-414.

Mitchell BD, Cauller LJ (2001) Corticocortical and thalamocortical projections to layer I of the frontal neocortex in rats. Brain Res 921:68-77.

Moore CI, Nelson SB (1998) Spatio-temporal subthreshold receptive fields in the vibrissa representation of rat primary somatosensory cortex. J Neurophysiol 80:2882-2892.

Mountcastle VB (1957) Modality and topographic properties of single neurons of cat's somatosensory cortex. J Neurophysiol 20:404-434.

Norton TT, Casagrande VA, Irvin GE, Sesma MA, Petry HM (1988) Contrast-sensitivity functions of W-, X-, and Y-like relay cells in the lateral geniculate nucleus of bush baby, Galago crassicaudatus. J Neurophysiol 59:1639-1656.

Penny GR, Itoh K, Diamond IT (1982) Cells of different sizes in the ventral nuclei project to different layers of the somatic cortex in the cat. Brain Res 242:55-65.

Perreault MC, Qin Y, Heggelund P, Zhu JJ (2003) Postnatal development of GABAergic signalling in the rat lateral geniculate nucleus: presynaptic dendritic mechanisms. J Physiol (Lond) 546:137-148.

Petersen CC, Hahn TT, Mehta M, Grinvald A, Sakmann B (2003) Interaction of sensory responses with spontaneous depolarization in layer $2 / 3$ barrel cortex. Proc Natl Acad Sci USA 100:13638-13643.

Prieto JJ, Peterson BA, Winer JA (1994) Morphology and spatial distribution of GABAergic neurons in cat primary auditory cortex (AI). J Comp Neurol 344:349-382. 
Radnikow G, Feldmeyer D, Lubke J (2002) Axonal projection, input and output synapses, and synaptic physiology of Cajal-Retzius cells in the developing rat neocortex. J Neurosci 22:6908-6919.

Ramon y Cajal S, DeFelipe J, Jones EG (1988) Cajal on the cerebral cortex: an annotated translation of the complete writings. New York: Oxford UP.

Rausell E, Jones EG (1991) Chemically distinct compartments of the thalamic VPM nucleus in monkeys relay principal and spinal trigeminal pathways to different layers of the somatosensory cortex. J Neurosci 11:226-237.

Reyes A (2001) Influence of dendritic conductances on the input-output properties of neurons. Annu Rev Neurosci 24:653-675.

Robinson DL, Petersen SE (1992) The pulvinar and visual salience. Trends Neurosci 15:127-132.

Simons DJ (1983) Multi-whisker stimulation and its effects on vibrissa units in rat SmI barrel cortex. Brain Res 276:178-182.

Soda T, Nakashima R, Watanabe D, Nakajima K, Pastan I, Nakanishi S (2003) Segregation and coactivation of developing neocortical layer 1 neurons. J Neurosci 23:6272-6279.

Stern EA, Maravall M, Svoboda K (2001) Rapid development and plasticity of layer 2/3 maps in rat barrel cortex in vivo. Neuron 31:305-315.
Sur M, Sherman SM (1982) Linear and nonlinear W-cells in C-laminae of the cat's lateral geniculate nucleus. J Neurophysiol 47:869-884.

Szabadics J, Lorincz A, Tamas G (2001) $\beta$ and $\gamma$ frequency synchronization by dendritic GABAergic synapses and gap junctions in a network of cortical interneurons. J Neurosci 21:5824-5831.

Williams SR, Stuart GJ (1999) Mechanisms and consequences of action potential burst firing in rat neocortical pyramidal neurons. J Physiol (Lond) 521:467-482.

Zhou FM, Hablitz JJ (1996a) Postnatal development of membrane properties of layer I neurons in rat neocortex. J Neurosci 16:1131-1139.

Zhou FM, Hablitz JJ (1996b) Morphological properties of intracellularly labeled layer I neurons in rat neocortex. J Comp Neurol 376:198-213.

Zhu JJ (2000) Maturation of layer 5 neocortical pyramidal neurons: amplifying salient layer 1 and layer 4 inputs by $\mathrm{Ca}^{2+}$ action potentials in adult rat tuft dendrites. J Physiol (Lond) 526:571-587.

Zhu JJ, Connors BW (1999) Intrinsic firing patterns and whisker-evoked synaptic responses of neurons in the rat barrel cortex. J Neurophysiol 81:1171-1183.

Zhu JJ, Lo FS (1998) Control of recurrent inhibition of the lateral posteriorpulvinar complex by afferents from the deep layers of the superior colliculus of the rabbit. J Neurophysiol 80:1122-1131. 